\title{
New Strategies for Anti-Inflammatory Drug Development
}

\section{Esra Küpeli Akkol*}

Department of Pharmacognosy, Faculty of Pharmacy, Gazi University, Etiler 06330, Ankara, Turkey

Inflammatory diseases are one of the major health problems worldwide. Acute and chronic inflammations are induced by several chemical mediators such as prostaglandins, leukotrienes and platelet-activating factor. Anti-inflammatory agents show their activities through several activity mechanisms [1]. Non-steroid antiinflammatory drugs (NSAIDs) are the most prescribed drugs for treatment of inflammatory diseases. The NSAIDs provide the patients with symptomatic relief, however, they do not modify the pathogenesis of inflammation [2]. Furthermore, prolonged use should be avoided due to severe side effects particularly on gastric mucosa. Therefore, searching for new drug candidates in the treatment of chronic inflammation has great importance.

The scientific researches on the biological effects of the medicinal plants led to the discovery and development of novel bioactive drug molecules. Indeed, natural products have proved to be a rich source of therapeutic agents. Due to the side effects caused mostly by synthetic drugs, research into natural products has advanced tremendously in academia and pharmaceutical companies. The consumer interest in such plant-based remedies is due to the lower cost of phytotherapy and the fact that many plant-based remedies are successfully replacing allopathic medicines in relieving malady symptoms.

For centuries, in rural areas, the efficacious plants have been used in simple formulations to treat several diseases. Inflammatory diseases are among the most common health problems treated with traditional remedies. In vivo and in vitro anti-inflammatory, antinociceptive and antipyretic evaluations of medicinal plants provide scientific evidence for the ethnomedicinal features. In the past few years, many studies have investigated the healing potential of higher plants with ethnobotanical histories. Many such plant-derived molecules have been isolated, identified and successfully introduced into international markets by pharmaceutical industries [3].

Particularly phenolic plant constituents such as flavonoids, phenolic acids and proanthocyanins were reported to modulate arachidonic acid metabolism. Similarly, a number of phenolic compounds were shown to be the active anti-inflammatory and antinociceptive compounds of folk remedies through bioassay-guided isolation procedures [4].

In an in vitro study, the extract from leaves of Cistus laurifolius (Cistaceae) was found to have inhibitory activity against PGE1and PGE2-induced contractions [5]. 3-O-methylquercetin isolated from this plant was shown to have inhibitory activity against prostaglandins. Anti-inflammatory and antinociceptive activities of 3,7-O-dimethyl- kaempferol was also reported [6]. Importantly, the anti-inflammatory potency of these flavonoids was found to be equal to that of indomethacin, without inducing any apparent acute toxicity or gastric damage. These compounds were also determined to have significant antinociceptive effects, as evidenced by inhibitory activity against phenylbenzo- quinone-induced writhing in mice. A mixture of kaempferol-3-O- $\beta$-D-galactoside with quercetin-3$O-\beta$-arabinopyranoside from Geranium pratense ssp. finitimum
(Geraniaceae) was reported to have remarkable anti-inflammatory and antinociceptive activities against carrageenan- and PGE2-induced paw edema in mice [7]. quercetin-3-O- $\beta$-glucopyranoside and quercetin3-O- $\beta$-galactopyranoside were previously isolated from Acaena magellanica (Rosaceae) were determined as potent anti-inflammatory and analgesic components [8]. These compounds were also found to be active against phenylbenzoquinone- induced writhing, indicating antinociceptive activity [7]. The main flavonoids, kaempferol-3,7dirhamnoside and quercetin-3,7-dirhamnoside from the leaves of Tilia argentea have been shown to possess significant anti-inflammatory and antinociceptive activites [9]. Anti-inflammatory activity of isoorientin (luteolin-6-C- $\beta$-D-glucoside), a C-glycosyl flavone, isolated from Gentiana olivieri Griseb. (Gentianaceae) was investigated by using the carrageenan-induced hindpaw edema model. The results have shown that this compound is more potent than indomethacin. Potent antinociceptive activity was also found against phenylbenzoquinoneinduced writhing in mice [10]. Isoorientin also exhibited high in vitro inhibitory activity against both thromboxane and leukotriene synthesis [11]. The anti-inflammatory and antinociceptive activities of the extracts from the Taxus baccata were investigated in another study. Taxoids and lignan derivatives were determined as the active antinociceptive constituents against phenylbenzoquinone-induced writhing test [12]. Similarly, lariciresinol and isolariciresinol were reported to possess potent in vitro inhibitory activity against tumor necrosis factor $\alpha$ (TNF- $\alpha$ ) production [13]. Moreover, lignan type compounds wikstromol and matairesinol from Daphne oleoides ssp. oleoides (Thymelaeaceae) were shown to have moderate inhibitory activity on TNF- $\alpha$ biosynthesis [14].

There are too many researches regarding the scientific biological activity evaluation of the traditionally used medicinal plants. It is obvious that folk medicines are the most favorable sources for novel drug discovery. By using in vivo bioassay- or in vitro activity-guided fractionation and isolation techniques, hundreds of active constituents have been identified. Hence, it would be reasonable to follow an ethnopharmacological approach using traditional knowledge to increase success in drug discovery and development.

\section{References}

1. Samuelsson B, Goldyne M, Granström E, Hamberg M, Hammarström S, et al (1978) Prostaglandins and thromboxanes. Annu Rev Biochem 47: 997-1029.

*Corresponding author: Esra Küpeli Akkol, Department of Pharmacognosy, Faculty of Pharmacy, Gazi University, Etiler 06330, Ankara, Turkey, Tel: +90 312 2023185; Fax: +90 312 2235018; E-mail: esrak@gazi.edu.tr

Received March 14, 2012; Accepted March 16, 2012; Published March 19, 2012

Citation: Akkol EK (2012) New Strategies for Anti-Inflammatory Drug Development. J Pharmacogenom Pharmacoproteomics 3:e118. doi:10.4172/21530645.1000e118

Copyright: (c) 2012 Akkol EK. This is an open-access article distributed under the terms of the Creative Commons Attribution License, which permits unrestricted use, distribution, and reproduction in any medium, provided the original author and source are credited. 
Citation: Akkol EK (2012) New Strategies for Anti-Inflammatory Drug Development. J Pharmacogenom Pharmacoproteomics 3:e118. doi:10.4172/2153$0645.1000 \mathrm{e} 118$

Page 2 of 2

2. Ford-Hutchinson AW, Bray MA, Cunningham FM, Davidson EM, Smith MJ (1981) Isomers of leukotriene B4 possess different biological potencies. Prostaglandins 21: 143-152.

3. Sumner J (2000) The natural history of medicinal plants. Timber Press, Portland, Orgeon, USA.

4. Yesilada $E$ (2008) Novel drug leads from Turkish medicinal plants with diverse pharmacological effects. Drugs Fut 33: 673.

5. Sadhu SK, Okuyama E, Fujimoto H, Ishibashi M, Yesilada E (2006) Prostaglandin inhibitory and antioxidant components of Cistus laurifolius, a Turkish medicinal plant. J Ethnopharmacol 108: 371-378.

6. Küpeli E, Yesilada E (2007) Flavonoids with anti-inflammatory and antinociceptive activity from Cistus laurifolius L. leaves through bioassayguided procedures. J Ethnopharmacol 112: 524-530.

7. Küpeli E, Tatli II, Akdemir ZS, Yesilada E (2007) Estimation of antinociceptive and anti-inflammatory activity on Geranium pratense subsp. finitimum and its phenolic compounds. J Ethnopharmacol 114: 234-240.

8. Feresin GE, Tapia A, Gutierrez RA, Delporte C, Backhouse Erazo N, et al. (2002) Free radical scavengers, anti-inflammatory and analgesic activity of
Acaena magellanica. J Pharm Pharmacol 54: 835-844.

9. Toker G, Küpeli E, Memisoglu M, Yesilada E (2004) Flavonoids with antinociceptive and anti-inflammatory activities from the leaves of Tilia argentea (silver linden). J Ethnopharmacol 95: 393-397.

10. Küpeli E, Aslan M, Gürbüz I, Yesilada E (2004) Evaluation of in vivo biological activity profile of isoorientin. Z Naturforsch C 59: 787-790.

11. Odontuya G, Hoult JR, Houghton PJ (2005) Structure-activity relationship for antiinflammatory effect of luteolin and its derived glycosides. Phytother Res 19: $782-786$.

12. 12. Küpeli E, Erdemoglu N, Yesilada E, Sener B (2003) Anti-inflammatory and antinociceptive activity of taxoids and lignans from the heartwood of Taxus baccata L. J Ethnopharmacol 89: 265-270.

13. Cho JY, Kim AR, Park MH (2001) Lignans from the rhizomes of Coptis japonica differentially act as anti-inflammatory principles. Planta Med 67: 312-316.

14. Yesilada E, Taninaka H, Takaishi Y, Honda G, Sezik E, et al. (2001) In vitro inhibitory effects of Daphne oleoides ssp. oleoides on inflammatory cytokines and activity-guided isolation of active constituents. Cytokine 13: 359-364. 